\title{
Clinical Excellence Awards-time for a fairer NHS rewards scheme
}

Ryan Essex, ${ }^{1}$ research fellow, Ishanka Talagala, ${ }^{2}$ consultant community physician, Olamide Dada, ${ }^{3}$ medical student, Mala Rao, ${ }^{4}$ director

${ }^{1}$ The University of Greenwich, Old Royal Naval College, Greenwich, London SE10 9LS, UK

${ }^{2}$ Ministry of Health, Sri Lanka

${ }^{3}$ School of Medicine, Cardiff University, Cardiff CF14 4YS, UK

${ }^{4}$ Ethnicity and Health Unit, Department of Primary Care and Public Health, Imperial College London, UK

Correspondence to: R Essex r.w.essex@gre.ac.uk

Ryan Essex and colleagues call for abolition of the Clinical Excellence Awards owing to their inherent divisiveness and persistent structural inequalities

Covid-19 has transformed the visibility of healthcare delivery, and public attitudes and perceptions related to the NHS have changed, potentially forever. The leadership shown by all NHS staff in managing the challenges of the pandemic leads to questions about how excellence is to be defined and how the unique contributions of individuals will and should be recognised and rewarded after covid-19.

The current NHS rewards system, known as the Clinical Excellence Awards (CEAs), which benefits consultant medical staff in England, was paused for the first time in 2020 owing to the pandemic and is currently undergoing a government consultation. ${ }^{1}$ This intermission is an opportunity to review these awards. We provide a brief overview of the scheme and discuss the lack of evidence to show that it is fairly distributed, incentivises individual or team performance, or improves patient outcomes. We call for abolition of the scheme and for input from all NHS staff to determine an equitable alternative.

\section{A brief history}

The system originally known as the Distinction Awards Scheme for hospital consultants was introduced at the inception of the NHS. Its original intention (at least in part) was to persuade the most senior members of the medical profession to end their opposition to the NHS. ${ }^{2}$ Regarded now as a performance related payment scheme, ${ }^{2}$ it has undergone several modifications over the years, but its core - a voluntary competitive process to identify and reward consultants providing the "highest quality" of service-remains unchanged. Does this 
apparently justifiable means to an end in 1948 deserve to be continued in the post-covid-19 era?

The Distinction Awards Scheme was criticised for many decades. ${ }^{3}$ In the 1980s, analyses found "iniquitous" allocation of awards, with women, younger consultants, those working in certain specialties (such as obstetrics and gynaecology, pathology, and dermatology), and those who worked in non-teaching hospitals far less likely to receive an award. ${ }^{4}$ This was further compounded by advisory committees that contained little to no diversity. ${ }^{4}$

The CEAs were launched in 2003 by the Advisory Committee for Clinical Excellence Awards (ACCEA) of the Department of Health (box 1). ${ }^{7}$ There are 12 levels of award. The levels have been developed over several years in consultation with representative bodies. A consultation published in 2001, for example, set out proposals to "reward commitment and excellence in the NHS." This was part of the new medical consultant contract with the new awards scheme coming into operation after 2004. Awards from level 1 (worth $£ 3016(€ 3500$; $\$ 4150)$ ) to 9 are awarded locally. Level 9 can also be awarded nationally (bronze; worth $£ 36$ 192), along with 10 (silver; $£ 47$ 582), 11 (gold; £59 477 ), and 12 (platinum; $£ 77320$ ). ${ }^{5-10}$ To put this in context, from April 2020, consultants in England were paid a base salary of $£ 82096$ to $£ 110683$ per year dependent on experience.

Payments are pensionable for local awards given before 2018 but not after. Local awards received before 2018 are held until retirement or voided due to gaining of a national award. Those received after 2018 last for up to three years. National CEAs at all levels remain pensionable and are held for five years as long as clinicians remain eligible. Applications to renew awards or attain an award at the next level are simultaneously possible. First renewals of a national award occur after four years, with subsequent renewals every five years thereafter to maintain continuity of payment for those who apply to renew and achieve (or better) the minimum standards based on successful scores of national excellence for attaining a new award at that level in that year. For those not achieving minimum standards, renewal at a lower level is possible if they meet the minimum standards of that level. A reversion scheme has been in place since 2018 to allow reversion to a pensionable local level 7 or 8 award for those applicants who fail to score highly enough to retain a national award. The local level awarded is based on the score attained in their renewal application. Renewal is highly likely; in 2017 and 2018, for example, only about 20\% of applications were unsuccessful. 811 
Box 1: Key milestones in the history of the NHS consultants awards schemes ${ }^{5}$ 1948-The Consultants Distinction Awards are introduced at the launch of the NHS "to attract and persuade the 'specialists' who through their reputation were influential in their profession, to allay their concern of loss of income and to overcome their strong opposition to the formation of the NHS"

1994-Discretionary points scheme (of lower financial value) introduced to "reward outstanding professional work of direct benefit to patient care in the local hospital or community, while the national Distinction Awards continue as a means of rewarding outstanding professional work of wider benefit to patients in the NHS as a whole" 2004-The Clinical Excellence Awards replace the Discretionary Points and Distinction Awards with a single scheme comprising both local (employer based) and national elements

2020 - The CEAs are paused "to enable consultants and managers to focus on immediate pandemic related priorities"

2021-The CEA process is resumed at local and national levels and a consultation entitled "Reforming the national Clinical Excellence Awards scheme" is opened on 24 March 2021 with a closing date of 16 June $2021 .^{6}$

The scheme aims to "recognise and reward consultant doctors and dentists and academic general practitioners (but not other GPs) who provide clear evidence of clinical excellence, demonstrating achievements that are significantly over and above what they would normally be expected to deliver in their roles. $" 81213$ The annual selection process involves a selfcompleted application describing the consultant's achievements across several domains (box 2). These include "providing a high quality service, developing a high quality service, leadership and managing a high quality service, research and innovation, and teaching and training." Applications for national awards are considered by one of 16 regional and national committees (including one for Wales) made up of approximately 24 members, including 11 professionals, six employers, and five lay people from a range of backgrounds. ${ }^{9}$ Committees rank applications against a scoring system, and applications above an agreed threshold receive a CEA. The 2021 round opened in December 2020 and closed in March 2021. For the 2021 round, supporting citations for new award applications were permitted only by accredited national nominating bodies, such as the medical royal colleges, Universities UK, and the BMA. ${ }^{9}$

\section{Box 2: A rough guide to the CEA application and assessment process}

1. Annual guidance published by the ACCEA for applicants, employers, and nominating bodies is reviewed, updated, and published on gov.uk at the commencement of each new round

2. Consultants on NHS contracts consider their eligibility and fill in the online application form for an appropriate level of award

3. Employer sign-off is completed and the form is submitted by the national deadline 
4. Consultants might seek a supporting citation from a specialist society or accredited national nominating body such as a medical royal college

5. ACCEA subcommittees and NHS trust based committees are convened to assess the national and local applications

6. Specialist societies and accredited national nominating bodies also submit citationsstatements supporting applications from their members and ranked listsrecommendations for who should get an award in priority order

7. ACCEA scores applications based on scoring guidance

8. The highest scoring applications that fall within the allocated number of awards nationally or are available in local organisations, depending on their consultant headcounts and budget allocation, are deemed successful.

National CEAs are awarded only to consultants working in England or Wales. No new CEAs have been awarded since 2013 in Northern Ireland, and the scheme has been frozen since 2010 in Scotland ${ }^{10}$. Consultants in Scotland can instead apply for discretionary points (still a form of financial reward) through their employer. In Wales, local CEAs have been replaced by commitment awards, which are available to consultants at the top of the pay scale who have satisfactory job plan reviews.

The CEA scheme and previous award schemes have never been extended to nonacademic GPs. ${ }^{5}$ We speculate that they were probably not considered for inclusion because of their "independent contractor status" - the NHS has made payments to general practices for services since its inception, ${ }^{14}$ from which individual GPs draw an income.

\section{At what cost?}

The funding for CEAs is substantial. Over the past few years, 2000-3000 consultants have held national awards at any one time, ${ }^{8}$ and around 300 national CEAs have been awarded annually between 2015 and 2019, although the overall spend for the scheme has declined (table 1).

Table 1 The total cost of the scheme in England (national awards)

\begin{tabular}{lccc}
\hline Financial year & $\begin{array}{c}\text { Total cost of CEAs in } \\
\text { England }\end{array}$ & $\begin{array}{c}\text { Total number of } \\
\text { awards }\end{array}$ & New awards \\
\hline $2019-20$ & $£ 125801942$ & 2061 & 300 \\
$2018-19$ & $£ 129587301$ & 1875 & 300 \\
$2017-18$ & $£ 136548561$ & 2601 & 300 \\
$2016-17$ & $£ 125530161.92$ & 2441 & 300 \\
$2015-16$ & $£ 121617117.34$ & 2765 & 300 \\
\hline
\end{tabular}

Source: ACCEA secretariat and ACCEA annual reports, Department of Health and Social Services. Note: ACCEA annual reports, detail numbers per 'award round' and not by financial year.

The expenditure for 2019-20 for national awards is similar to the total NHS cost of outpatient family planning clinics ( $£ 106517468$ ) or outpatient child and adolescent mental health attendances in England (£138 338646$).{ }^{15}$ In 2006 it was calculated that, if the scheme 
had been scrapped, every consultant would have been entitled to a pay rise of $£ 10000$ a year, ${ }^{2}$ but the "dangling carrot" of a CEA might have kept the salary of most consultants down. ${ }^{4}$ If the 2019 budget for CEAs was redistributed to the consultants ( $n=50875$ consultants) ${ }^{16}$ alone, they would get a rise in salary of around $£ 2400$. A more modest pay increase for consultants would enable other doctors $(n=71571)$ in the hospital and community health services to share in a small pay rise.

Do CEAs overcome the shortcomings of the original scheme? Attempts at reform and some progress have been made to tackle past issues, such an inequalities between genders and specialties, but many concerns remain. Two key problems are the scheme's immutable unfairness and the lack of evidence that the scheme benefits patient care.

\section{Fair and equitable for all doctors?}

An ongoing concern relates to the scheme's application and assessment processes. They are inherently complex and resource intensive for employers, consultants, nominating bodies, and scoring committees. Anonymisation is attempted, but the application asks for description of individual achievements, which will likely lead to disclosure of the applicant to those on the award subcommittees. A lack of inherent reliability is also a major issue. Analysis of the 2014 round of national awards found variation in the assessment of applications, ${ }^{12}$ mostly accounted for by inconsistencies in assessors' scoring. Scoring differences, test-retest reliability, and regional variations have, to our knowledge, never been investigated by domain of assessment, across specialties, or by gender and ethnicity. Equivalence in comparing excellence between medical specialties and between academics and clinicians delivering care might be impossible. The domains of assessment have never been assessed for their internal consistency or validity across the clinical specialties.

The issue of how the CEA process measures sustained achievement also remains problematic. ACCEA guidance routinely states that eligibility for an award is dependent on sustained achievements over time. ${ }^{13}$ But CEAs assessed each year take no account of rankings from previous years. There is no requirement to hold any local award to apply for a national award. ${ }^{9}$ This might incentivise applications from younger consultants, but a senior consultant who is assessed to be "just below the threshold" rank one year has no guarantee of an award the next year, even if they have been able to add substantially to their achievements, with fresh applicants always being able to overtake them in subsequent years. This shifts focus from longer term sustained excellence to shorter term achievements. 
A final problem relates to the fundamental questions of how excellence is assessed and whether this can be captured by a written application alone, which in substantial part depends on a level of clarity, coherence, and fluency in English. This is likely to disadvantage several groups, but especially those whose first language is not English, such as international medical graduates. To date, variations in CEAs between UK and international medical graduates have not been examined.

These inherent shortcomings are likely to have contributed to the disparities now seen by specialty, ethnicity, and gender. ${ }^{813}$ Annual ACCEA reports have shown variation among medical specialties in CEA recipients, ${ }^{89}$ with higher representation of consultants from medicine and surgery and under representation of other specialties such as psychiatry and anaesthetics. $^{81718}$ In 2018 the need to act on this was acknowledged by the ACCEA. ${ }^{11}$

Research has also shown a gender pay gap of 2.8\% among consultants in NHS England, in favour of male consultants. ${ }^{19}$ The Independent Review into Gender Pay Gaps in Medicine in England confirmed that CEAs "play an important role in creating the overall gender pay gap," although other allowances and payments contribute to the majority of the gap. ${ }^{20} \mathrm{~A}$ disproportionately greater number of awards are given to men every year. ${ }^{12}$ Historically, there has been a lower success rate (awards as a proportion of applications) among female consultants in receiving new awards, ${ }^{21} 22$ and this under representation is exacerbated at higher award levels. ${ }^{12}$ Fewer applications are received from female consultants. ${ }^{17} 18$

Black and ethnic minority consultants made up almost $40 \%$ of the workforce in $2019,{ }^{23}$ but an ethnic pay gap of $4.9 \%$ favouring white consultants in England, highlighted in a 2018 study, is likely to continue today. ${ }^{24}$ National awards given to black and ethnic minority consultants had risen to $20 \%$ in 2017 , but substantial ethnic variations persist, with this difference becoming greater as the level of the award increases. ${ }^{17} 1825$ Nationally, fewer applications are received from black and ethnic minority consultants, and fewer black and ethnic minority consultants are successful in their applications compared with their white counterparts. ${ }^{8}$ Some evidence indicates that black and ethnic minority consultants apply in higher numbers locally but are less successful in their applications. ${ }^{25}$

\section{A good way to incentivise performance?}

Annual appraisals have been mandatory requirements for all consultants for several decades; applying for a CEA is optional and disconnected from the annual appraisal outcome. The CEA application asks whether an appraisal has been undertaken, but not the content of 
the appraisal. Thus, consultants could receive exceptional appraisals year after year but be overlooked for a CEA. The opposite could also be true.

CEAs have been criticised for rewarding individual performance at the expense of team performance. ${ }^{26}$ Healthcare is a team endeavour and team performance deserves recognition. Furthermore, there is no evidence that CEAs lead to improvements in patient health and wellbeing. This does not necessarily mean an evidence of absence, but research indicates that most performance related pay systems do not improve performance in healthcare and other sectors. Evidence from systematic reviews suggests the impact of pay for performance schemes is, at best, minimal. ${ }^{27-29}$ Other studies call for caution, warning that such incentives don't work. ${ }^{30}$ Further afield, inequality related to pay in teams of elite athletes generally has a negative effect on team performance. ${ }^{31}$ At best, the effects of performance based pay are mixed. At worst, such schemes can have a negative effect on performance. ${ }^{32}$ Across the UK countries (all of which have different systems related to performance payments), CEAs have not been reported to have any effect on consultant vacancies, retention, or recruitment or the delivery of care more generally. ${ }^{33}$

\section{A better way forward}

Doctors deserve to be paid well, but they also deserve pay equality. CEAs should be abolished and replaced with an equitable alternative that is capable of incentivising team excellence among all consultants and set in a framework that is fair to all doctors and all staff. The public and all NHS staff should be involved in shaping a modern, effective, equitable pay for performance scheme that is tailored to the needs of the NHS.

Consultants have begun questioning whether it is time to abandon the laborious competitive process and to find fairer ways to distribute the local CEA budget. ${ }^{34}$ Staff at Lincolnshire Partnership NHS Foundation Trust have been considering how to make the distribution of its CEAs fairer; a discussion given a welcome impetus by the national 2020 guidance ${ }^{35}$ to NHS trusts to distribute the award money equally among eligible consultants, to enable clinicians and managers to focus on immediate pandemic related priorities.

The covid-19 pandemic has shone a light on the everyday professionalism of all NHS staff. We must question whether it is appropriate to reward 300 national CEA "winners" when all NHS staff deserve recognition. Our analysis draws attention to the scheme's inherent divisiveness and persistent structural inequalities, including by race and gender. The medical leadership has a responsibility to champion health and social equality, and to do that 
credibly, it might begin by putting its own house in order, with equality placed above other interests in leading the establishment of a fair and just rewards system in the NHS.

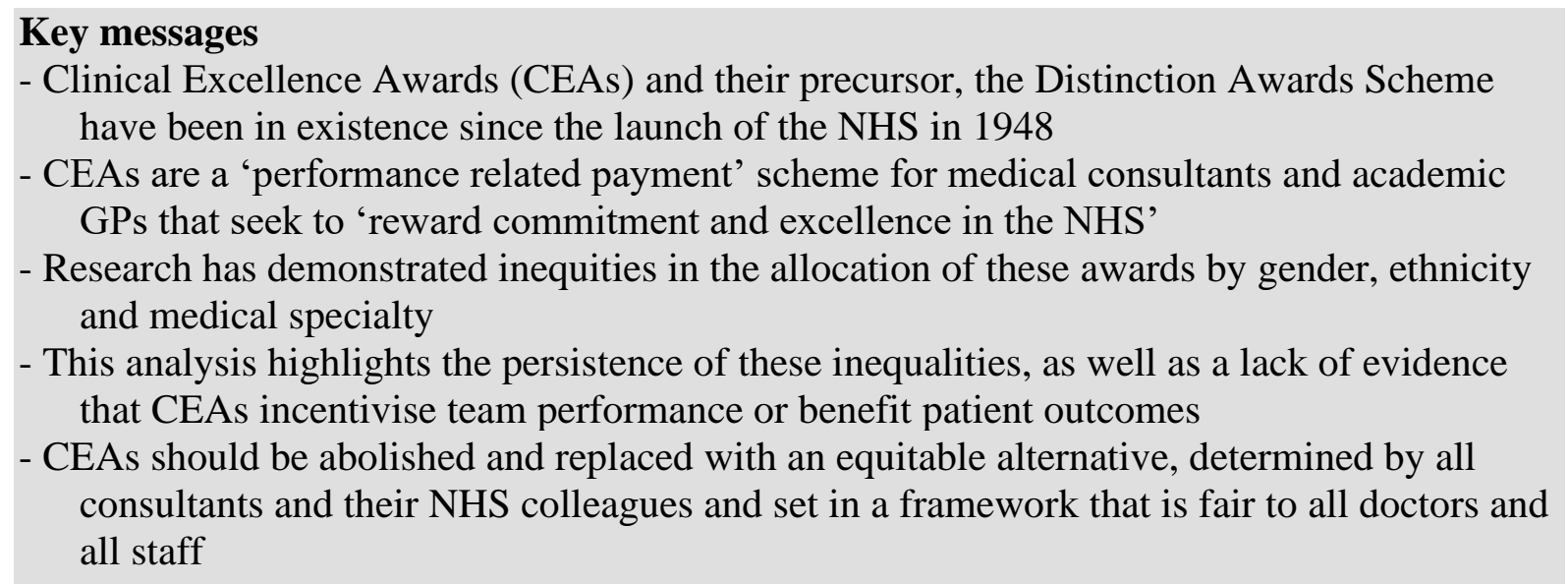

We thank Azeem Majeed and John Appleby for their helpful comments on earlier versions of this manuscript. We are also grateful to Ananta Dave for advising us on recent changes to the awards scheme and on measures introduced by her NHS trust for a more equitable distribution of local CEAs and to Surash Surash for his insights and advice, drawing on his research on CEAs. Finally, we would also like to thank Fraz Mir who shared with us his valuable insights on the inequitable distribution of the awards.

Contributors and Sources: MR conceived this article. IT, OD, and MR contributed to an initial draft. RE and MR worked on subsequent drafts and all authors contributed to the final draft of this paper.

Patient involvement: Patients were not involved in the drafting of this article.

Competing interests: We have read and understood BMJ policy on declaration of interests and have the following interests to declare: None.

1 Open consultation: Reforming the national Clinical Excellence Awards scheme. https://www.gov.uk/government/consultations/reforming-the-national-clinicalexcellence-awards-scheme

2 Abel P, Esmail A. Performance pay remuneration for consultants in the NHS: is the current system fair and fit for purpose? J R Soc Med 2006;99:487-93.

3 Esmail A, Abel P, Everington S. Discrimination in the discretionary points award scheme: comparison of white with non-white consultants and men with women. BMJ 2003;326:687-8.

4 Bruggen P, Bourne S. The distinction awards system in England and Wales 1980. Br Med J (Clin Res Ed) 1982;284:1577-80.

5 Review Body on Doctors' and Dentists' Remuneration. Review of compensation levels, incentives and the Clinical Excellence and Distinction Award schemes for NHS consultants Cm 8518. December 2012.

https://assets.publishing.service.gov.uk/government/uploads/system/uploads/attachme nt_data/file/226727/DDRB_CEA_Cm_8518.pdf 
6 Pay for doctors. https://www.healthcareers.nhs.uk/explore-roles/doctors/pay-doctors

7 Advisory Committee on Clinical Excellence Awards. Guide to the NHS Consultants' Clinical Excellence Awards Scheme. 2003.

8 Advisory Committee on Clinical Excellence Awards. 2019 ACCEA Annual Report (covering the 2018 Awards Round). 2019.

9 Advisory Committee on Clinical Excellence Awards. Guide for applicants National Clinical Excellence Awards: 2021 awards round. December 2020. https://assets.publishing.service.gov.uk/government/uploads/system/uploads/attachme nt_data/file/941633/clinical-excellence-awards-guide-for-applicants-2021.pdf

10 British Medical Association. Consultant award schemes and clinical excellence awards (CEA), 2020. https://www.bma.org.uk/pay-and-contracts/pay/consultantaward-schemes/consultant-award-schemes-and-clinical-excellence-awards-cea

11 Advisory Committee on Clinical Excellence Awards. 2018 ACCEA Annual Report (covering the 2017 Awards Round). 2018.

12 Campbell JL, Abel G. Clinical excellence: evidence on the assessment of senior doctors' applications to the UK Advisory Committee on Clinical Excellence Awards. Analysis of complete national data set. BMJ Open 2016;6:e011958.

13 Advisory Committee on Clinical Excellence Awards. Guide for assessors National Clinical Excellence Awards: 2019 awards round. 2019

14 NHS. Primary care commissioning. 2021. https://www.england.nhs.uk/contactus/privacy-notice/how-we-use-your-information/our-services/primary-carecommissioning/

15 National Cost Collection for the NHS. 2018/19 National Cost Collection data. https://www.england.nhs.uk/national-cost-collection/\#support</eref>

16 NHS Hospital and Community Health Service (HCHS) Monthly workforce statistics. NHS Digital. September 2020.

17 Advisory Committee on Clinical Excellence Awards. Advisory Committee on Clinical Excellence Awards: Annual Report (covering the 2015 awards round). 2016.

18 Advisory Committee on Clinical Excellence Awards. Annual Report (covering the 2016 awards round). 2017.

19 Appleby J, Schlepper L. The gender pay gap in the English NHS United Kingdom: Nuffield Trust. 2018. https://www.nuffieldtrust.org.uk/news-item/the-gender-pay-gapin-the-english-nhs

20 Department of Health and Social Care. Mend the Gap: The Independent Review into Gender Pay Gaps in Medicine in England. 2020. Available from DHSC on request.

21 Kalra VS, Abel P, Esmail A. Developing leadership interventions for black and minority ethnic staff: A case study of the National Health Service (NHS) in the U.K. J Health Organ Manag 2009;23:103-18.

22 Lambert TW, Goldacre MJ, Vallance E, Mallick N. Characteristics of consultants who hold distinction awards in England and Wales: database analysis with particular reference to sex and ethnicity. BMJ 2004;328:1347.

23 NHS workforce 2020. https://www.ethnicity-facts-figures.service.gov.uk/workforceand-business/workforce-diversity/nhs-workforce/latest\#by-ethnicity-and-grademedical-staff

24 Appleby J. What is the ethnicity pay gap among NHS doctors? Nuffield Trust 2018. https://www.nuffieldtrust.org.uk/news-item/what-is-the-ethnicity-pay-gap-amongnhs-doctors 
25 Surash S, Pearce K. The Surash Pearce Report: A comprehensive review into ethnic pay-gap and workforce development at The Newcastle upon Tyne Hospitals NHS Foundation Trust. 2019. https://www.newcastlehospitals.nhs.uk/content/uploads/2020/09/Surash-Pearce-Report-2019_low_res.pdf

26 Bloor K, Maynard A. Rewarding healthcare teams. BMJ 1998;316:569-70.

27 Mathes T, Pieper D, Morche J, Polus S, Jaschinski T, Eikermann M. Pay for performance for hospitals. Cochrane Database Syst Rev 2019;7:CD011156.

28 Eijkenaar F, Emmert M, Scheppach M, Schöffski O. Effects of pay for performance in health care: a systematic review of systematic reviews. Health Policy 2013;110:115-30.

29 Alshamsan R, Majeed A, Ashworth M, Car J, Millett C. Impact of pay for performance on inequalities in health care: systematic review. J Health Serv Res Policy 2010;15:178-84.

30 Jha AK. Time to get serious about pay for performance. JAMA 2013;309:347-8.

31 Bucciol A, Foss NJ, Piovesan M. Pay dispersion and performance in teams. PLoS One 2014;9:e112631.

32 Pohler D, Schmidt JA. Does pay-for-performance strain the employment relationship? The effect of manager bonus eligibility on nonmanagement employee turnover. Person Psychol 2016;69:395-429

33 British Medical Association. Consultant workforce shortages and solutions: now and in the future. https://www.bma.org.uk/media/3430/bma-consultants-retentionpaper.pdf

34 Mir F. Why consultants could do more for other frontline staff [electronic response to Coombes R. Covid-19: Frontline doctors speak out about struggle to maintain care standards]. BMJ 2021. https://www.bmj.com/content/371/bmj.m4971/

35 NHS Employers. Local clinical excellence award arrangements from 1 April 2018. https://www.nhsemployers.org/pay-pensions-and-reward/medical-staff/consultantsand-dental-consultants/local-clinical-excellence-awards-arrangements-from-1-april2018 